\title{
Management of Complicated Crown-Root Fracture Using Newer Radiographic AIDS - A Case Report
}

\author{
Dolly Rathod ${ }^{1 *}$ and Sanjyot Mulay ${ }^{2}$ \\ ${ }^{1}$ Department of Conservative \& Endodontics, Terna Dental College, India \\ ${ }^{2}$ Department of Conservative \& Endodontics, Patil Dental College, India
}

Received: August 22, 2017; Published: January 17, 2018

*Corresponding author: Dolly Rathod, Department of Conservative \& Endodontics, Terna Dental College, Nerul, Navi-Mumbai, Maharashtra India,

\section{Abstract}

Crown-root fractures are complex traumatic injuries that require multidisciplinary management and may afford uncertain prognosis. Diagnosis of such cases is often difficult. With the newer radiographic aids like CBCT, the diagnosis is more definite and hence treatment outcome can be more predictable. This case report discusses the use of newer radiographic aids and treatment options for fractured teeth with the concept of intentional re plantation as an option to manage complicated crown-root fractures in permanent anterior teeth.

Keywords: Cone beam computerized tomography; Intentional re plantation; Re - attachment

\section{Introduction}

Management of patient with traumatic injuries to their dentition is an integral part of general dental practice. Trauma to oral structures like teeth has a great psychological impact on the minds of patients. Since anterior teeth help in maintaining the form, function \& esthetics, a treatment plan which would not compromise on any of these values with minimal treatment time is most desirable. Aesthetics plays an important role in contemporary dentistry, especially emphasizing beauty and health. A smile is considered beautiful if it imitates a natural appearance, with wellaligned teeth and defined anatomical shapes [1-3].

\section{Case Report}

A 20 years old male patient reported to the department of Conservative Dentistry and Endodontics, Dr. D. Y. Patil Dental College and Hospital, with a chief complaint of broken tooth in upper front region of the jaw. No extra oral abnormality was detected. On intra oral examination

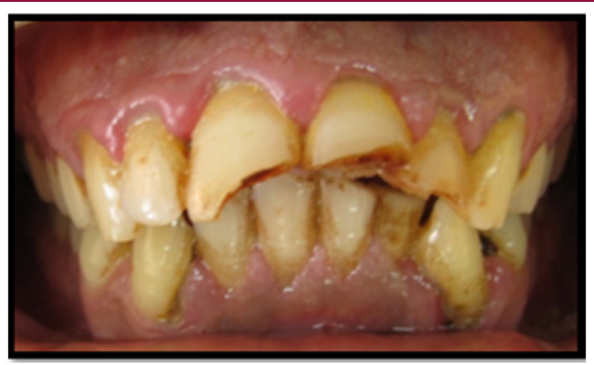

Figure 1a: Fracture lines in 11, $21 \& 22$. a. Ellis Class III fracture was seen with 11 \& Ellis Class VI fracture was seen with $21 \& 22$ which extended from buccal to the palatal aspect sub gingivally (Figure $1 \mathrm{a}$ ).

b. Grade II mobility was present with $11,21 \& 22$.

\section{Investigations}

a. IOPA radiograph of 11, 21 and 22 was taken which revealed a fracture line through enamel, dentin and pulp chamber in the coronal structure with $11,21 \& 22$ (Figure 1 b).

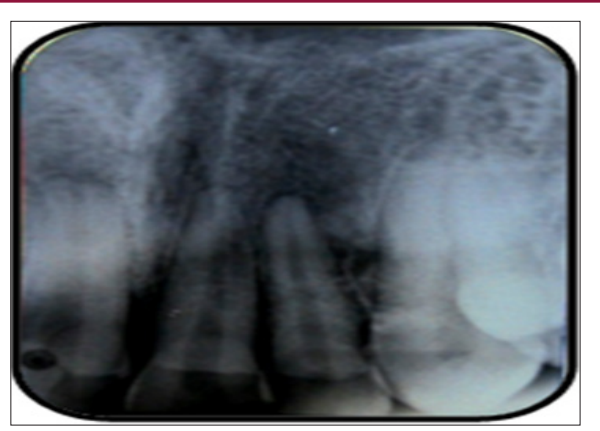

Figure 1b: IOPA with 11, $21 \& 22$.

b. Pulp Vitality Test for 11, 21 and 22 was performed, using electric pulp test where all three teeth showed delayed response.

c. Orthopantomogram (OPG) was done to rule out involvement of any other teeth or presence of abnormality. 

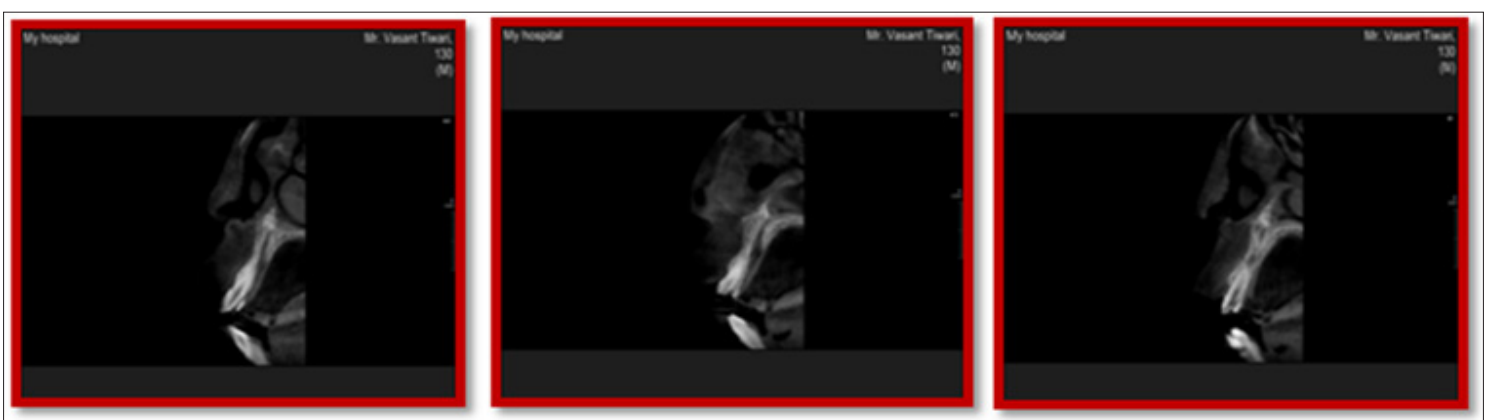

Figure 2: CBCT views with 11, 21 \& 22.
a. $\quad$ CBCT view with 11
b. $\quad$ CBCT view with 21
c. $\quad$ CBCT view with 22

d. Cone beam computed tomography (CBCT) was performed to locate the exact position \& extent of the fractured line present with 11, 21 \& 22 (Figures 2a, 2b \& 2c).

e. Blood investigation such as (complete hierogram, bleeding time and clotting time) was done.

\section{Various Treatment Options}

a. Intentional re plantation after reattachment.

b. Removal of fractured fragments followed by surgical / orthodontic extrusion of tooth.

c. Extraction and replacement with immediate implant placement.

d. Extraction and fixed prosthesis.

\section{Treatment Plan}

After discussion at length with the patient, option A was selected i.e. intentional re plantation after reattachment. A written informed consent was undertaken by the patient. Pre-surgical antibiotic coverage was initiated one day prior to surgery. Treatment plan drawn for Ellis Class III fracture with 11 \& Ellis Class VI fracture with $21 \& 22$ as follows

\section{Phase 1 : Surgical Phase}

i. $\quad$ Correction of Ellis Class III fracture with 11:

a. Surgical reattachment

b. Root canal treatment

ii. $\quad$ Correction of Ellis Class VI fracture with 21 \& 22:

a. Intentional surgical extraction of $21 \& 22$

b. Root canal treatment

c. Root reinforcement

d. Reattachment of fragments

e. Re plantation of $21 \& 22$

\section{Phase 2 : Restorative Phase}

a. Composite restorations done for $11,21 \& 22$.

\section{Treatment}

\section{Phase 1 : Surgical Phase}

Local anesthesia (2\% Xylocaine 1:80,000 adrenaline) was administered. Supragingival \& sub gingival deposits were removed using ultrasonic scalars. A full thickness bucco-lingual mucoperiosteal flap was raised with a sulcular incision using no 15 blade. Fractured fragments of 11, 21 \& 22 were removed traumatically and stored in normal saline (Figures 3a \& 3b).

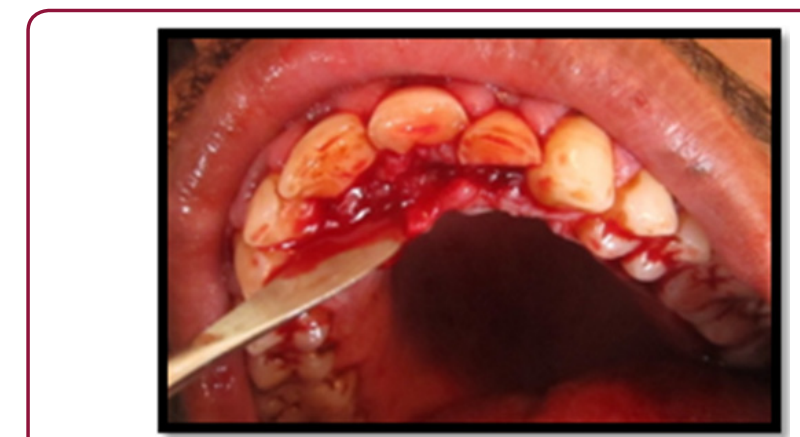

Figure 3a: Mucosal flap raised with 11, 21 \& 22.

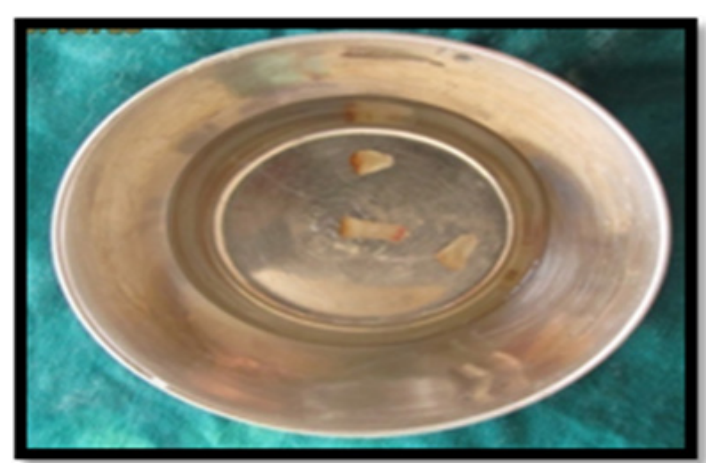

Figure 3b: Tooth fragments with 11, 21 \& 22.

Management Of Ellis Class Iii Fracture With 11

Grooves for auxiliary retention were prepared in both the fractured crown fragment and at the fractured site of the remaining tooth. Fractured area was etched with $37 \%$ phosphoric acid for 10-15 seconds. Then bonding agent (Adper Single bond, 3M ESPE) was applied to the fragments and light cured for 20 seconds. The fractured crown fragment was then reattached with remaining 
tooth using flow able composite resin. The excess resin was removed with an excavator and was light cured for 40 seconds from both buccal and palatal aspects. Later root canal treatment was done for 11.

\section{Management Of Ellis Class VI fracture with $21 \& 22$}

After removal of fractured fragments, intentional extraction of $21 \& 22$ was done and were kept in normal saline (Figures $4 \mathrm{a} \& 4 \mathrm{~b}$ ).
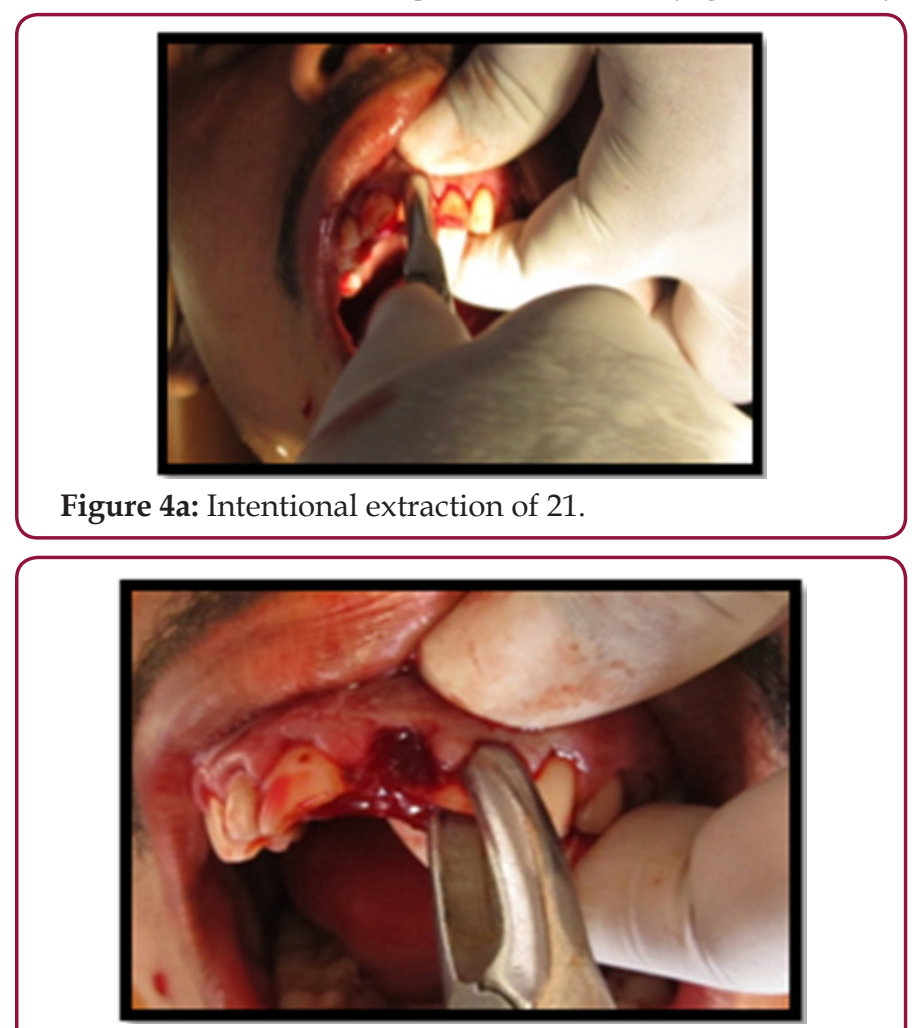

Figure 4b: CBCT views with 11, 21 \& 22.

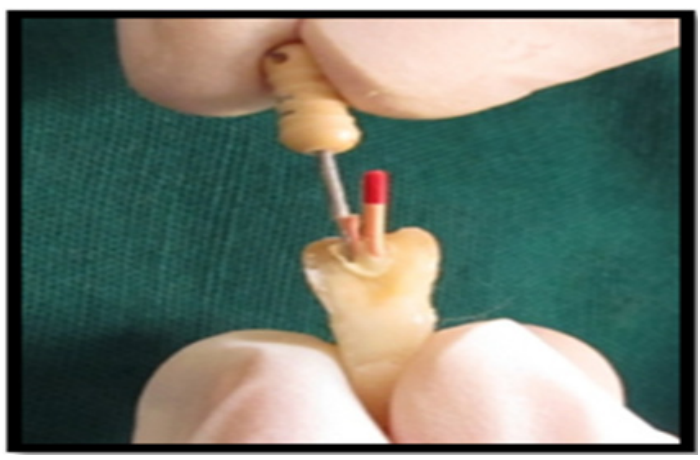

Figure 5: Obturation.

\section{Root canal treatment}

An access cavity was prepared in 21 \& 22; pulp extirpation was done \& the working length was determined. The root canals were instrumented with $\mathrm{K}$ files until an apical stop of ISO \#50 and canals preparation was performed using the standard step-back technique of cleaning and shaping. The root canals were copiously irrigated with $3 \% \mathrm{NaOCl}$ followed by a final rinse with sterile saline. The prepared teeth were dried with paper-points and filled with laterally condensed gutta-percha using AH Plus root canal sealer (Dentsply) (Figure 5).

\section{Root Reinforcement}

The gutta-percha was partially removed from the root canal using heated instrument, leaving at least $5 \mathrm{~mm}$ of the apical plug of gutta-percha to maintain a good apical seal. A suitable size fiber post (Double Taper Light Post, Illusion R.T.D.) were selected for 21 \& 22 and checked for proper fit and cemented with self adhesive universal composite resin cement (Rely X U100, 3M ESPE) (Figure $6)$.

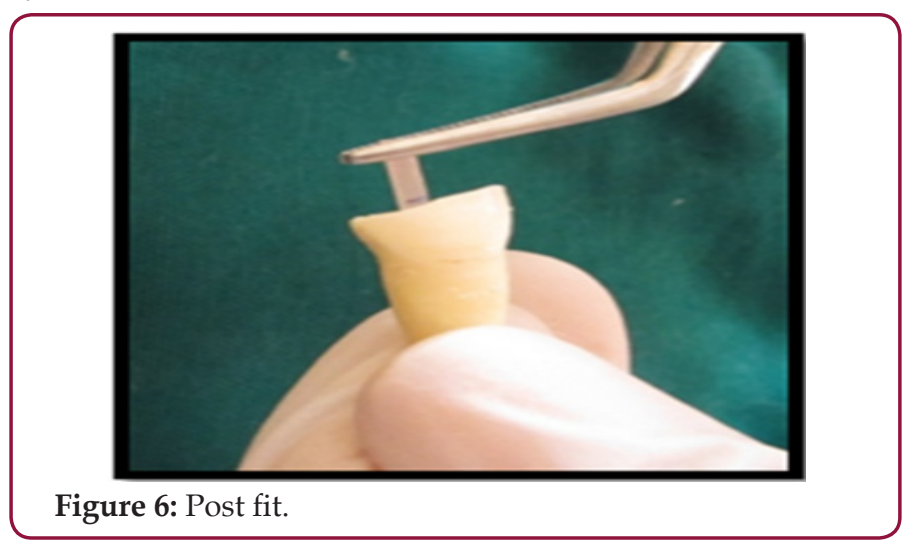

Reattachment of Fragments

Grooves in dentine were prepared in both the fractured crown fragment and at the fractured site of the remaining tooth. Fractured area was etched with $37 \%$ phosphoric acid for $10-15$ seconds. Then bonding agent was applied to the fragments and light cured for 20 seconds. The fractured crown fragment was then reattached with remaining tooth using flow able composite resin. The excess resin was removed with an excavator and was light cured for 40 seconds from both buccal and palatal aspects (Figures 7a \& 7b).

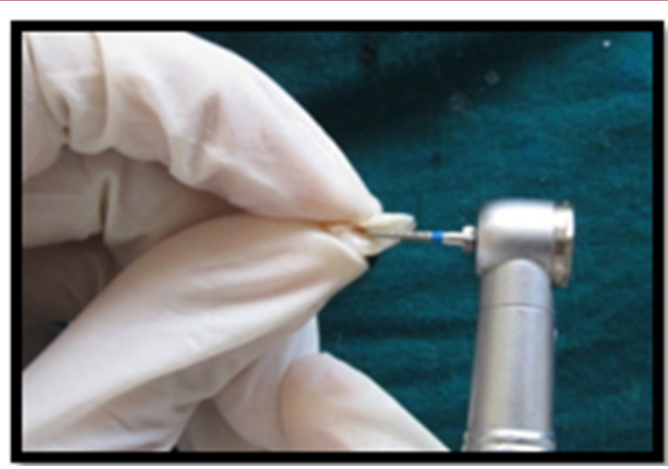

Figure 7a: Grooves made on detached tooth fragments.

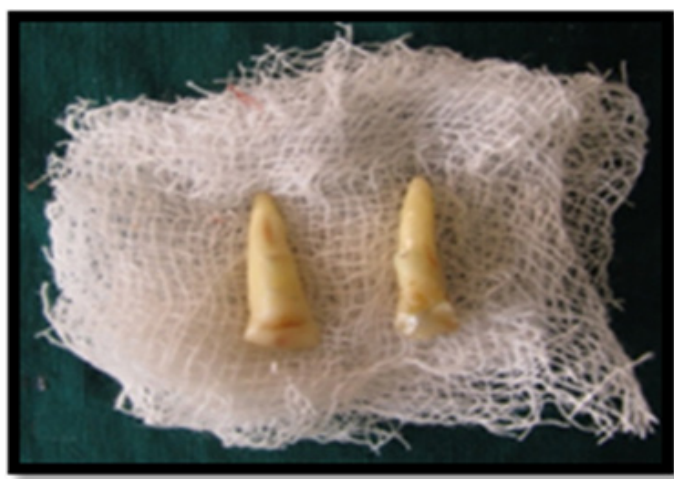

Figure 7b: Teeth with fragments attached for $21 \& 22$. 


\section{Re plantation of $21 \& 22$}

Socket was irrigated with cold saline before re plantation, intentional re plantation done for 21 and 22. Immediate postoperative view of $21 \& 22$ (Figure 8a), Flap was repositioned and sutured with 3-0 black silk. Splinting from 13-33 was placed for immobilization of the teeth (Figure $8 \mathrm{~b}$ ). Post-operative radiograph was taken with 21 \& 22 (Figure 8c). Post-operative instructions were given to the patient. 24 hours follow up showed no significant postoperative pain or discomfort. One week later, clinical examination Revealed uneventful healing. Sutures \& splint for ridiculers support was removed. Oral hygiene procedures were reinforced. At 4th week the labial splint was removed.

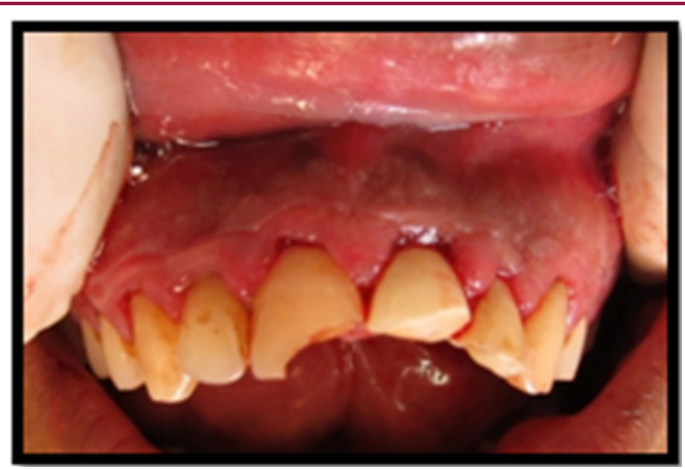

Figure 8a: Immediate post-operative view of $21 \& 22$.

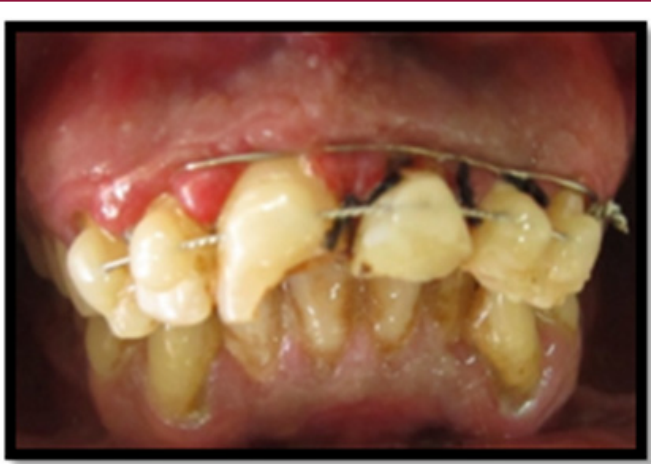

Figure 8b: Splinting was placed for immobilization of the teeth.

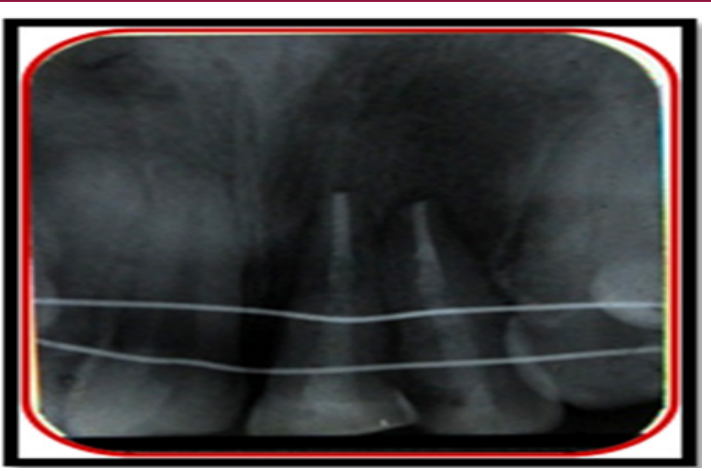

Figure 8c: Post-operative Radiograph with 21 \& 22.

\section{Phase 2 : Restorative Phase}

$11,21 \& 22$ were slightly roughened, etching was done with $37 \%$ phosphoric acid for 10-15 seconds, 5th generation bonding agent Adper Single bond (3M ESPE) was applied with applicator brush and light cured for 20 seconds, followed by Filtek Z350 (3M ESPE) composite resin for built-up of remaining tooth structure (Figure 9).

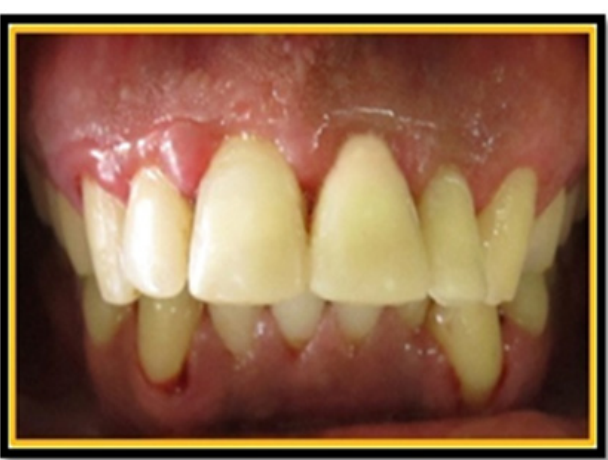

Figure 9: Composite builtup with 11, $21 \& 22$.

\section{Maintenance Phase}

Periodic follow-up was done every 3 months. Radiographs were taken for evaluating osseous healing (Figures 10a \& 10b).

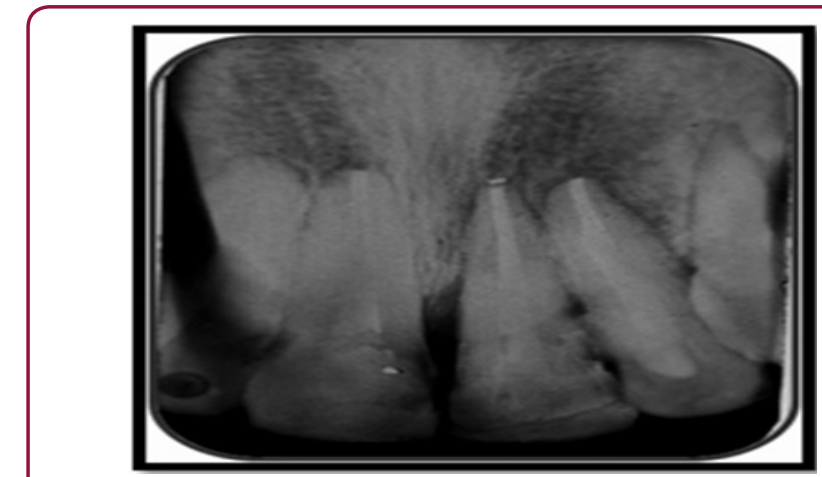

Figure 10a: 3 months follow-up.

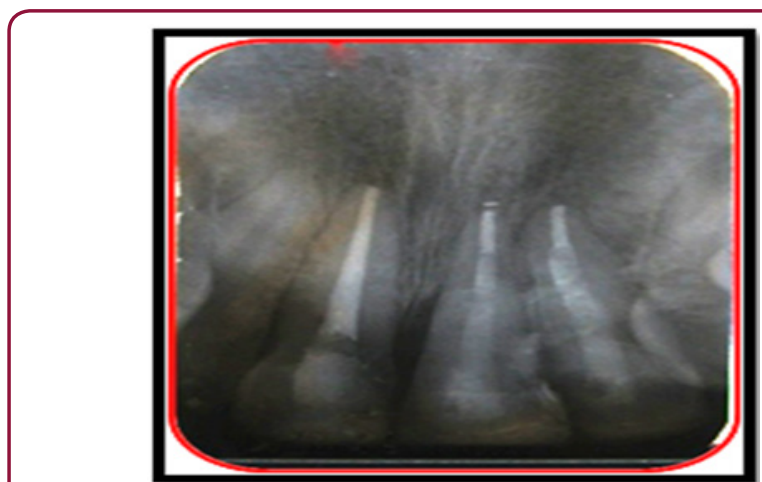

Figure 10b: 6 months follow-up.

\section{Discussion}

Traumatic injuries are frequent now days with rising number. Owing to occupational and social commitments, patients expect quick results. Current 2D technologies are film and digital based. Huumonen and Ørstavik, stated that radiographic limitations exist, because radiographs are 2D in nature and clinical or biologic features may not be reflected in radiographic changes [4]. Evidence is compelling that these limitations may be overcome through CBCT imaging. Nair \& Nair [5] summarized CBCT technology proving it useful for localization and characterization of root canals, treatment planning of periapical surgery, and detection of root 
fractures in extracted teeth. Mora and co-workers used a bench top higher solution LCBCT device to demonstrate the superiority of this technology over conventional 2D imaging [6].

With current newer radiographic aids diagnosis is more accurate \& prognosis is more predictable. With the advent of adhesive dentistry re-attachment of a fractured tooth fragment is a viable option. Reattachment procedure has several advantages such as esthetics, conservative procedure, obtaining healthy periodontal attachment, original tooth contours, color and translucency $[7,8]$. As the reattachment procedure does not preclude any future treatment so whenever an intact fragment is available, reattachment of fractured fragment should be considered as a viable first treatment option [9]. Liew [10] described the reattachment procedure in a case report and stated that prognosis of this procedure as it can act as 'a short to medium term temporary restoration which has the potential for indefinite service'. Kanca J [11] reported a reattachment procedure with the fragment being intact at 5 year follow-up visit; however their case had a pulpal exposure at the time of trauma which was sealed with a dentine adhesive. The success rates of reattached fragments has been seen to be up to $90 \%$ for the parameters of periodontal, pulpal and color harmony for a follow up of up to 24 months [12]. Auxiliary methods of retention, such as labial and lingual bevel have a positive effect on the Shear Bond Strength of the reattached fragment [13].

Contemporary resin adhesives and resin post systems allow strong durable bond to dentin providing a "Monoblock concept". In this case, a glass fiber post was used to retain the coronal segment. The post interlocks the two separate fragments and minimizes the stress on the remaining tooth structure. Intentional re plantation has some advantages which include being an easier, less-invasive, less time-consuming, and less-costly procedure. In addition, root canal therapy is better performed extra orally [14]. The indications for intentional re plantation include failure of root canal treatment, anatomic limitations, and perforations in areas inaccessible to surgery, persistent chronic pain, or patient management $[15,16]$.

In this case, intentional re plantation was chosen as the treatment option on the basis of the clinical indication and patient's desire to retain own teeth. When teeth are fractured sub gingivally, the fractured crown to residual root ratio will not be reassuring and, thus, an increasing number of affected teeth may require support from adjacent teeth. Need to splint a fractured tooth to adjacent teeth to increase mechanical resistance $[17,18]$. Filtek Z350 (3M ESPE) is a nanocomposite resin. Having superior esthetic and wear characteristics, high polish ability, and superior handling characteristics, they are marketed as universal composites providing "Life like Aesthetics" to restorations. Their esthetic qualities make this composite suitable for anterior buildups; while their agglomerated nano -clusters interspersed with micro-sized particles give them wear resistant characteristics.

\section{Conclusion}

With the use of newer radiographic aids and a systematic treatment planning, rehabilitation of complicated crown-root fracture can be achieved in a conservative and predictable way.

\section{Conflict of Interest Statement}

I declare that I do not have any commercial or associative interest that represents a conflict of interest in connection with the work submitted.

\section{References}

1. Sundfeld RH, Croll TP, Briso AL (2007) Considerations about enamel microabrasion after 18 years. Am J Dent 20(2): 67-72.

2. Sundfeld RH, Rahal V, Croll TP (2007) Enamel microabrasion followed by dental bleaching for patients after orthodontic treatment-case reports. J Esthet Restor Dent 19(2): 71-78.

3. Sundfeld RH, Sundfeld Neto D, Machado LS (2009) A eficiência do clareamento dental: relato de casos clínicos. Dentistry Brasil 1(14): 2228.

4. Huumonen S, Ørstavik D (2002) Radiological aspects of apical periodontitis. Endodontic Topics 1(1): 3-25.

5. Nair M, Nair U (2007) Digital and advanced imaging in endodontics: a review. J Endod 33(1):1-6.

6. Maria A Mora, André Mol, Donald A Tyndall, Eric M Rivera, et al. (2007) In vitro assessment of local computed tomography for the detection of longitudinal tooth fractures. Oral Surg Oral Med Oral Pathol Oral RadiolEndod 103(6): 825-829.

7. Arhun N, Ungor M (2007) Re-attachment of a fractured tooth: A case report. Dent Traumatol 23(5): 322-326.

8. Zorba YO, Ozcan E (2007) Reattachment of coronal fragment using fiberreinforced post: a case report. Eur J Dent 1(3): 174-178.

9. Murchison DF, Burke FJT, Worthington RB (1999) Incisal edge reattachment; indications for use and clinical technique. British dental journal 186: 614-619.

10. Liew P (1988) Reattachment of original tooth fragment to a fractured crown Case report. Australian Dental Journal 33(1): 47-50.

11. Kanca J (1996) Replacement of a fractured incisor fragment over pulpal exposure: A long-term case report. Quintessence International 27(12): 829-832.

12. Yilmaz Y ,Zehir C, Eyuboglu O, Belduz N (2008) Evaluation of success in the reattachment of coronal fractures. Dent Traumatol 24(2): 151-158.

13. Michelle Chazine, Maurizio Sedda (2011) Dental Traumatology 27(1): $15-18$.

14. Kratchman S (1997) Intentional replantation. Dent Clin North Am 41(3): 603-617.

15. Peer M (2004) Intentional replantation - a last resort treatment or a conventional treatment procedure? Nine case reports. Dent Traumatol 20(1): 48-55.

16. Dumsha TC, Gutman JC (1985) Clinical guidelines for intentional replantation. Compend ContinEduc Dent 6(8): 604-608.

17. RR Welbury (1997) Traumatic injuries to the teeth, in Richard R Welbury Pediatric De Dentistry Oxford, Scotland, UK, pp. 225-251.

18. Andreasen JO, Andreasen FM (2000) Extrusion and lateral luxation in Andreasen JO, Andreasen FM Essentials of traumatic injuries to the teeth, Munksgaard, Copenhagen, Denmark, pp. 85-101. 


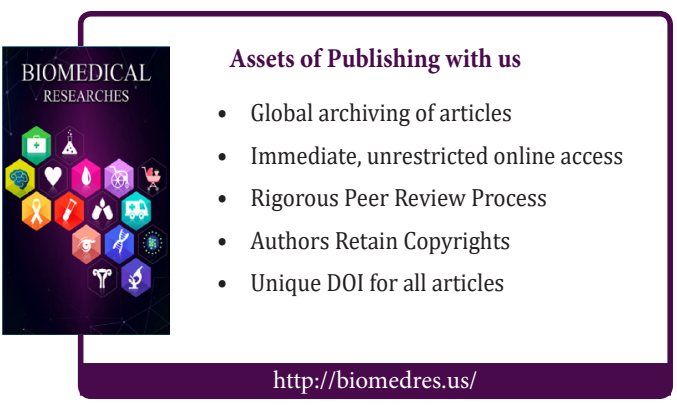

